\title{
A AUTORIA NA IMPROVISAÇÃO EM DANÇA
}

\author{
Mariane Araujo Vieira ${ }^{1}$
}

\begin{abstract}
RESUMO
Este artigo, parte integrante de uma pesquisa de mestrado em andamento, aborda a questão da autoria nos trabalhos de composição em tempo real em dança. Assim, é proposto neste texto a ideia de que a autoria é vista como uma organização de informações coletivas e compartilhadas elaboradas por um sujeito socialmente inscrito. Dessa forma, a ideia de originalidade e ineditismo de uma obra é questionada, assim como a ideia de autoria como uma função permanente e fixa. Além disso, é abordado que o/a improvisador/a desempenha uma função-autor/a nos trabalhos apresentados em tempo real.
\end{abstract}

PALAVRAS-CHAVE: autor/a, composição em tempo real, criação, improvisador/a

\section{LA AUTORÍA EN LA IMPROVISACIÓN EN DANZA}

\section{RESUMEN}

Este artículo forma parte de una investigación de maestría y discute la idea de la autoría en la composición en tiempo real en la danza. Propongo que la autoría es un conjunto de informaciones colectivas y compartidas elaboradas por um sujeto socialmente integrado. De esa forma, cuestiono la ideia de originalidad y de carácter inédito así como la ideia de la autoría como una función permanente y fija. Además, abordo que el improvisador desarrola un rol de autor en las composiciones en tiempo real.

PALABRAS-CLAVE: autor/a, composición en tiempo real, creación, improvisador/a

\section{AUTHORSHIP IN IMPROVISATION IN DANCE}

\begin{abstract}
This paper is part of a master's research in progress and approaches the authorship of dance compositions in real time. We propose that authorship is a set of collective and shared information elaborated by a socially integrated subject. Thus, we question the idea of originality of a work and the idea of authorship as a permanent, fixed role. In addition, we discuss that improvisers play the role of authors in compositions in real time.

KEYWORDS: author, composition in real time, creation, improviser

\footnotetext{
${ }^{1}$ Artista, improvisadora, pesquisadora e professora de dança. Mestrado em andamento pelo Programa de Pós-Graduação em Artes Cênicas pela Universidade Federal de Uberlândia, com bolsa FAPEMIG, orientado pelo Prof ${ }^{\circ}$ Dr $^{\circ}$ Jarbas Siqueira Ramos. E-mail: marianedanca@gmail.com.
} 
A improvisação em dança ganha, a partir da década de 1980, um papel essencial na dança contemporânea (WEBER, 2015, p. 16), reformulando ideias sobre coreografia, espetáculo e padrões estéticos da cena e do corpo. Por meio de artistas que não se enquadravam em contextos de grande produção artística e de entretenimento, a improvisação foi se tornando um modo de criar, apresentar, pesquisar e questionar vários parâmetros vigentes e hegemônicos no âmbito artístico. Um desses parâmetros é a ideia de autoria e criação na improvisação em dança, tema que será discutido neste artigo, e que é parte de uma pesquisa de mestrado vinculado ao Programa de Pós-Graduação em Artes Cênicas pela Universidade Federal de Uberlândia.

Sobre a ideia de autoria, no senso comum (influenciado por um pensamento do balé clássico), o autor e criador de uma obra em dança ganharia o status de coreógrafo, significando aquele que criou o trabalho artístico, diferente daquele que a executou, comumente recebendo o nome de bailarino/a. No sec. XX e XXI essas nomenclaturas foram se alterando e se adaptando ao fazer da dança moderna e pós-moderna. Já em um contexto contemporâneo, o termo coreografia' (do grego 'coreo', dança e 'grafia', escrita ou desenho) deixa de se associar a uma escrita da dança para se relacionar a uma composição em dança, isto é, uma composição coreográfica, que seria uma forma menos limitada de entender esse termo e que amplia diversas formas de criar e compor na contemporaneidade. Essa mudança de perspectiva foi necessária com o advento de tantas possibilidades de fazer dança que não se enquadravam ao estereótipo de coreógrafo/a e do/a bailarino/a. Alguns exemplos dessas criações seriam os happenings, as ações performáticas e de site specific em dança, a composição em tempo real e outros modos. Assim, para abarcar esses novos fazeres, o termo coreografia também se ampliou de forma que, como explica Ana Mundim (2015, p. 44) em seu artigo $O$ que é uma coreografia, "A coreografia e a composição coreográfica, portanto, sejam consideradas confluentes ou dissidentes, [pois]

\footnotetext{
${ }^{2}$ Por considerar esse assunto muito amplo sugiro a leitura dos textos no livro $A$ cena em foco: artes coreográficas em tempos líquidos organizado por Marcia Almeida (2015).
} 
partem do mesmo princípio: o corpo e seus sentidos em experiência criativa dentro de uma proposta dramatúrgica”.

Assim como a ideia de coreografia foi expandida para além da escrita, da execução de movimentos ou de uma partitura de movimentos, o termo coreógrafo também sofreu diversas alterações e entre elas a noção de criador/coreógrafo, principalmente para se referir aos trabalhos colaborativos. Suzi Weber (2015) afirma que uma geração de artistas como Merce Cuunigham, Anna Halprin, Trisha Brown, Steve Paxton, Pina Baush, Rudolf Laban, o coletivo na Judson Church e o Butô foram responsáveis por substituir “o binário coreógrafo/intérprete por colaborações artísticas [...] flexibilizando, desse modo, a forte hierarquia do coreógrafo como criador único e "patrão da obra artística" (WEBER, 2015, p. 14).

Nesse contexto, principalmente nas ações coletivas e colaborativas, a obra artística ganha uma dimensão mais democrática que valoriza o/a bailarino/a como criador/a e como sujeito que elenca e negocia os elementos da cena. Uma das possibilidades de criação menos hierárquica é quando alguém de um grupo artístico (não necessariamente o coreógrafo ou o diretor) propõe estímulos e provocações ao/a bailarino/a, e este/a responde com os próprios vocabulários corporais e de uma perspectiva singular. Essa mudança traz à tona a discussão sobre o termo intérprete e intérpretecriador e que Sandra Nunes (2002) vai identificar nessa modalidade a necessidade de diferenciar os termos: criador-intérprete e intérprete-criador. Segundo ela,

Enquanto o segundo [intérprete-criador], ainda que coloque sua abordagem
pessoal à obra que dança, seja criada por ele ou por outrem, o processo de pesquisa
habitualmente reproduz ou rearranja padrões de movimento já existente. Já o
criador- intérprete busca uma assinatura a partir do seu próprio corpo, num
processo investigativo. Articula novas hipóteses que estabelecem possibilidades de
relações entre movimentos até então não previstas num corpo que dança [...] O que
é construído em seu próprio corpo não é facilmente transferido para outro corpo
(NUNES, 2002, p. 95).

Por meio dessa perspectiva, o sujeito que antes era visto como um receptor e repetidor de movimentos coreografados por outra pessoa "superior", ganha mais autonomia seja um processo mais "roteirizado", 
sendo intérprete-criador, seja em um mais autoral (normalmente em solos) como criador-intérprete. Consequentemente, nesse processo, ser criativo, multidisciplinar, com um variado vocabulário corporal passou a requerer habilidades cobiçadas na dança, dentro de um contexto atual (dos últimos 60 anos), que demanda do intérprete a capacidade de resolver, de forma criativa e singular, as proposições, estímulos e questões da cena artística.

Essas novas formas de entender o papel do sujeito que cria e dança em cena abriu espaço e reforçou a possibilidade de um modo de compor que se dá em tempo real, não pré-estabelecido e elaborado pelo sujeito que dança. Nesse caso, na composição em tempo real, essas "funções" entre quem cria, quem executa, quem provoca ou quem escolhe o que vai ou não para a cena são diluídas no processo e na prática de apresentação com público. O/a improvisador/a se torna, assim, responsável pela escolha dos vocabulários de movimentos, da organização dos elementos cênicos, das relações entre artistas e público e da forma de lidar com o inesperado que vão traçar em conjunto a dramaturgia da obra.

Essa responsabilidade não exclui que um coletivo tenha um diretor ou um provocador da obra que direciona as estruturas composicionais, por mais que elas sejam improvisadas na cena. Ela, na verdade, desierarquiza a concepção de um único criador/autor da obra, entendendo, assim, que na composição em tempo real há criadores/improvisadores/as que dançam na relação entre corpos e na relação composicional singular que é coletiva.

Para exemplificar esses modos de organização cito alguns exemplos ${ }^{3}$ de grupos que trabalham com uma direção definida e com artistas/criadores/performers, são eles: o Núcleo Improvisação em Contato com direção de Ricardo Neves, com os trabalhos Urban Ferral, Relation X e Em busca do Peso Perdido; O Núcleo de Improvisação que tem na direção Zélia Monteiro, com trabalhos como Percurso Transitório; Área de Risco e Porque tenho essa forma?; O Núcleo Artérias dirigido por Adriana Grechi, com os trabalhos Protestos, Escuro Invisível e Fronteiras Móveis; e o Grupo

\footnotetext{
${ }^{3}$ Para não ficar excessivo os exemplos, cito no máximo três trabalhos de cada coletivo, considerando que há muito outras obras que vão nessa mesma perspectiva.
} 
Silenciosas dirigido por Diogo Granato, com os trabalhos Nosso primeiras estórias, Nove e Puerpério.

Também, segue alguns exemplos de grupos que trabalham com a criação compartilhada e improvisação: o Coletivo Lugar Comum, com o trabalho A voz do movimento; o Conectivo Nozes com o trabalho Sobre Pontos, Retas e Planos; o Coletivo Construções Compartilhadas, com o trabalho $O$ engenheiro que virou maçã; o grupo Radar1, com o trabalho Menu; o Substantivo Coletivo, com o trabalho Corpos (in)dóceis e Soma: Variações sobre o sensivel; e a Cia. Damas em Trânsito e os Bucaneiros, com os trabalhos Partilhas poéticas em contato, Sobre ruas e rios e Espaço Invisíveis.

Com enfoque nestes últimos exemplos, em que a criação é compartilhada em todo o seu processo de criação e apresentação, Bárbara Silva (2012), por meio da experiência no Grupo Radar1, identifica que o trabalho de composição em tempo real convoca "um tipo de autonomia que implica na descentralização da autoria, de modo que todos são coautores e corresponsáveis pela cena” (SILVA, 2012, p. 76). Ainda, ela explica que é através dos encontros, que ela chama de "ensaios", é que as competências criativas são compartilhadas e amadurecidas, possibilitando e potencializando um "um jeito coletivo de criar assuntos/temas nas composições improvisadas" (SILVA, 2012, p. 76). Alguns apontamentos que ela grifa nesse modo compositivo é que:

Ao analisarmos a concepção e encenação de Menu, observamos como a ação colaborativa entre agentes da cena (dançarinos e músico) e suas consignas compositivas (distribuição geográfica, figurino, número de dançarinos, qualidade sonora), constituem o que podemos considerar como parte fundante da dramaturgia da obra coreográfica. Afora o fato desta montagem não ter um coreógrafo ou diretor (todos os envolvidos agem como coautores e exercem lideranças provisórias na feitura das cenas), de forma que a cada apresentação podemos ter diferentes tessituras a partir do que surge das suas possíveis combinações (SILVA, 2015, p. 79).

Nesse tipo de ação, as tomadas de decisões são individuais/autorais e se colocam inseridas no conjunto. Isso significa, que o/a improvisador/a decide, não só pelos seus desejos e percepções, mas naquilo que se configura enquanto coletivo. Segundo Harispe (2014, p. 68), a natureza coletiva faz 
com que "os princípios de reciprocidade, mútua cooperação e conexão somático/cognitiva entre os integrantes estejam assegurados pelo jogo da empatia: a tomada-de-decisão tem lugar numa atmosfera cinestésica integrada". Assim, as escolhas da cena no coletivo precisam da relação entre os corpos para definir um ambiente de improvisação e criação, e no caso de improvisadores solistas a ambiência é criada pelas estruturas físicas e elementos acidentais do lugar em que se dança (HARISPE, 2014, p.71).

Por meio dessa reflexão, o fato de a improvisação permitir essa tomada de decisão instantânea em um determinado espaço-tempo cênico, é suficiente para tornar o intérprete o autor da obra? Quem cria a cena na composição em tempo real: o indivíduo, o coletivo ou a própria dramaturgia da obra? Será que ainda cabe o termo "autoria" nos fazeres dos/as improvisadores/as? Ou a autoria é um princípio do pensamento moderno que é propagado e valorizado ainda hoje, não cabendo no contexto da improvisação em dança na atualidade?

Para abordar as questões da autoria e originalidade, Jussara Setenta, observa que não é possível pensar o sujeito isolado, inserido em sua própria criatividade, que se fundamenta "na existência de um original, uma propriedade particular de um dono único" (SETENTA, 2008, p. 89), uma vez que o corpo que dança, na contemporaneidade, é um corpo socialmente inscrito, que organiza informações que são coletivas e compartilhadas. Nesse sentido, a criação de uma obra não é autoria de um sujeito único, especial, diferenciado, mas sim de um corpo agenciador, organizador, constituído de muitos outros corpos que estão em relação, colaboração e cooperação, e que "os modos de promover os rearranjos daquilo que compartilha com os outros é que são só seus" (SETENTA, 2008, p. 89). Ainda, Setenta complementa que, nesse caso, o sujeito "passa a ser tratado como sendo a reunião de uma coleção de informações em determinado estado, um estado que também sempre se transforma, pois o processo de troca e contaminações não para" (SETENTA, 2008, p. 91).

Em relação a essa questão da invenção inédita do artista, abro um parêntese para abordar os estudos sobre criatividade desenvolvidos por 
Murilo Gun". Ele defende o termo "combinatividade"5 para falar de criatividade e parte da ideia de que tudo que se "cria" (ideias, produtos, serviços, obra artística, soluções) são combinações de experiências já vividas que são organizadas e dispostas de formas diferentes e, aí sim, singulares. Para Gun (2020), a criatividade é a imaginação aplicada para imaginar uma combinação nunca antes feita entre coisas que estão no seu repertório com o objetivo de resolver um problema e que, dessa forma "Toda solução criativa é uma combinação de referências, é uma combinação de inspirações. Eu gosto de falar que é uma combinação de inputs" (GUN, 2020) ${ }^{6}$.

O que é criado (enquanto obra, ideia, movimento, solução) se torna parte de um fluxo vasto e não limitado de informações que se relacionam em todas as direções em diferentes contextos e sujeitos. Neste sentido, a ideia de autoria não deixa de existir, mas é atualizada para afirmar que um sujeito é constituído de outros sujeitos e que, por isso, este "passa a entender as suas ações como sendo as de um reorganizador. O resultado da reorganização é autoral, mas não no sentido de original. É autoral a partir de compartilhamentos, de processos de contaminação" (SETENTA, 2008, p. 92).

Outra forma que complementa essa ideia de autoria é feita por Gilsamara Moura e Lucas Valetim no artigo $O$ processo de criação colaborativa e a questão da autoria na dança: novos paradigmas e outros entendimentos. No texto, eles se apropriam dos estudos do filósofo Giorgio Agamben para defender uma distinção entre o autor e a função-autor. A definição deste último se descreve como:

[...] um regime particular de apropriação, que sanciona o direito de autor e, ao mesmo tempo, a possibilidade de distinguir e selecionar os discursos [...] a possibilidade de autenticar os textos, constituindo-os em cânone ou, pelo contrário, a possibilidade de certificar o seu caráter apócrifo; a dispersão da função enunciativa simultaneamente em mais sujeitos que ocupam lugares diferentes, e,

\footnotetext{
${ }^{4}$ Professor de Criatividade e Fundador da Keep Learning School. Para acessar a biografia dele acesse: https://murilogun.com.br/.

${ }^{5}$ Outros nomes para o conceito de combinatividade apontados por Murilo Gun são: Possível adjacente de Steve Johnson; bissossiação (é quando dois sistemas de referência, dois universos, eles se colidem e ao se colidir, esses universos, eles criam algo novo) de Arthur Koestler; Remix de Kirby Fergunson; Steal like an artist de Austin Kleon; e Mash-up.

6 Transcrição da fala do Murilo Gun transmitida no curso online chamado Gravidade Zero, organizado pela Keep Learning School. Curso disponibilizado no ano de 2020.
} 
por fim, a possibilidade de construir uma função transdiscursiva, que constitui o autor, apara além dos limites de sua obra, como -instaurador de discursividade (AGAMBEN, 2007, p. 56 apud ROCHA;MOURA, 2017, p. 9).

Nesse contexto, a função da autoria seria regular, organizar e limitar circunstâncias particulares para adentrar no fluxo de livre circulação, compartilhamento e manipulação. Essas reflexões atravessam a questão dos direitos autorais e que é respondida por Nirvana Marinho da seguinte maneira: “[...] assinar algo todos nós fazemos, deixamos marcas das singularidades do nosso fazer sobre tais ideias. Não podemos perder de vista: outro alguém vai se apropriar disso e refazer novas teias (MARINHO, 2007, p. 2). Essa reflexão também é abordada no livro "Roube como um artista" de Austin Kleon (2013), em que diferencia o roubo do plágio. Neste texto, o autor grifa que nada é original, tudo é roubado. A criação, nesse sentido, seguiria o ciclo na ordem: você "rouba, estuda, rouba de vários, credita e transforma as coisas" (KLEON, 2013, s/p). Dessa forma, o roubo seria o ato de "se apossar de elementos pré-existentes para lapidá-los em busca de algo inédito" (MENINI, 2019). Diferente disso, o plágio seria aquilo que degrada e que imitia sem citar referências. Um trecho interessante que ele cita é: "Todo artista ouve a pergunta: De onde você tira as suas ideias? O artista honesto responde: Eu roubo. Como o artista olha para o mundo? Primeiro, você descobre o que vale a pena roubar, depois você segue para a próxima etapa. Isso é tudo. (KLEON, 2013, s/p).

Partindo dessas reflexões, toda autoria é um roubo, uma combatividade, uma organização singular de coisas já criadas e que pode aparecer de forma mais direta ou diluída nos processos artísticos em dança. Gilsamara e Lucas apontam (2017) que em processos colaborativos pode haver a existência de uma autoria em rede, ou melhor, autoria em rede que se organizam através da função-autor exercida por diferentes corpos.

Esse apontamento se torna importante para pensar a função-autor de um/a improvisador/a em cena, pois, nos trabalhos de improvisação, é valorizado, além de ser um ponto essencial, as escolhas feitas pelos corpos que dançam. Isto é, a forma como "se dar a ver" as ações e as escolhas dramatúrgicas que acontecem em tempo real. Assim, mesmo que grupos de 
improvisação tenham diretores que assumam a função de autoria da obra, o/a improvisador/a também assume essa função que é compartilhada e se dá na relação com os outros corpos improvisadores/criadores/autores/as.

Nesse sentido, é importante também sinalizar que a possibilidade e a liberdade de criar, nesse modus de composição em tempo real, inclui dar a ver as memórias corporais e os vocabulários de movimentos apreendidos que se conectam e se combinam no tempo-espaço da cena. Entendendo assim, que as ideias e ações que o improvisador escolhe "apresentar" partem de uma gama de aprendizados já corporificados e selecionados que se reorganizam com o que está na cena, criando assim algo singular, o que não pressupõe originalidade em sua concepção tradicional, mas sim a elaboração e reelaboração de combinações e relações estimuladas pelo ambiente (e tudo que o compõe), sendo que na improvisação elas não são pré-estabelecidas. Dessa forma, a questão da autoria fica mais clara na improvisação quando ela está diluída no fluxo de informações que são elaboradas em cena e se torna uma das funções de organização e tomada de decisão do/a artista. Afinal, escolher implica decidir o que está ou não em cena, excluindo milhares de possibilidades de relação, de movimento, de ação, priorizando a escolha de uma proposição. Assim, a tomada de decisão se relaciona à um pensamento de dramaturgia da cena, sendo o/a improvisador/a corresponsável pelos nexos de sentidos que são estruturados no trabalho artístico. Nesse sentido, uma com-posição provoca uma reorganização de novas posições e de novas decisões.

Por fim, o/a improvisador/a que dança articula as próprias vivências, memórias e experiência sensíveis que são construídas individualmente e socialmente (de forma simultânea) com os elementos da cena que podem ser pré-estabelecidos ou não, e com o que se dá no tempo-espaço da cena, para assim constituir essa dança que é autoral e compartilhada ao mesmo tempo.

\section{CONCLUSÃO}

Sem a intenção de resolver essas questões da autoria e considerando esse tema amplo e delicado, este artigo sugeriu algumas reflexões que 
podem contribuir na verticalização desse assunto na improvisação. Assim, pensar a autoria, criação e originalidade de um trabalho em composição em tempo real em dança inclui entender o contexto histórico, social e cultural em que esses termos foram inseridos e reinventados ao longo dos anos no campo da dança. Assim como a improvisação como modo de apresentação é relativamente novo da área da dança, o termo improvisador/a enquanto função-autor da obra também se dá na contemporaneidade, e que sugere ainda diversas reflexões a serem feitas tanto no meio prático/artístico quanto no meio acadêmico.

Dessa forma, foi apresentado neste texto que a ideia de autoria como criador de algo inédito, ideia que prevalece durante séculos no campo das artes, se reorganiza perante os fazeres artísticos contemporâneos. E, de forma específica na dança, a concepção dos termos coreógrafos, diretores, bailarinos/as, intérpretes-criadores, se diluem em um fluxo de relações mais horizontais e dinâmicas, que são ressignificados por cada artista ou coletivos em dança. Essas reformulações foram necessárias principalmente no fazer improvisacional, em que a figura de coreógrafo se dilui, ou mesmo de desfaz, entre os/as improvisadores/as, valorizando, assim, novas formas de criar e tornando estes artistas autores e responsáveis pela cena.

Concluo assim, identificando o fazer improvisacional na composição em tempo real como um fazer que é autoral, no sentido de organizar de modo singular as informações coletivas, compartilhadas e elaborados por um sujeito que é socialmente inscrito. Nesse sentido, o improvisador assume uma função-autor que não é permanente ou fixa, e muito menos inédita ou original, mas que se dá no acontecimento da cena e que é compartilhada com aqueles que dançam e que a presenciam. Nesse sentido, na improvisação não há um autor/criador da obra, mas sim vários/as autores/as que assumem a responsabilidade da composição e da elaboração de uma dramaturgia dançada. 


\section{REFERÊNCIAS}

AGAMBEN, Giorgio. Profanações. Trad. Selvino J. Assman. 2. ed. São Paulo: Boitempo, 2007 apud ROCHA, Lucas. Valentim.; MOURA, Gilsamara. O processo de criação colaborativa e a questão da autoria na dança: novos paradigmas e outros entendimentos. In: ENICECULT - I Encontro Internacional de Cultura, Linguagens e Tecnologia do Recôncavo, 2017, Santo Amaro. Anais do ENICECULT - I Encontro Internacional de Cultura, Linguagens e Tecnologia do Recôncavo. Santo Amaro: ENICEULT, 2017. v. 1. p. 1-14.

ALMEIDA, Marcia Soares (Org.). A Cena em foco: artes coreográficas em tempos líquidos. Brasília: Editora IFB. Brasília: Editora IFB, 2015, p. 23 48.

HARISPE, Leonardo Andrés Mouilleron. A improvisação-dança nas coordenadas do composicional. Dissertação (Mestrado). Pós-Graduação em Artes Cênicas, Universidade Federal da Bahia, Salvador, 2014.

KLEON, Austin. Roube como um artista: 10 dicas sobre criatividade. Trad. Leornardo Villa-Forte. Editora: Rocco Ltda.

MARINHO, Nirvana. Autoria: qual é a da dança?. Idança.net, São Paulo, 21 ago. 2007.

MENINI, Lais. Os perigos do plágio. Literama, 2019. Disponível em: https://literama.com.br/os-perigos-do-plagio/. Acesso em: 9 maio 2020.

MUNDIM, Ana Carolina da Rocha. O que é coreografia? In: ALMEIDA, Marcia Soares (Org.). A Cena em foco: artes coreográficas em tempos líquidos. Brasília: Editora IFB. Brasília: Editora IFB, 2015, p. 23 - 48.

NUNES, Sandra Meyer. O criador-intérprete na dança contemporânea. Revista Nupeart, Florianópolis, v.1, n.1, p.83-96, 2002.

ROCHA, Lucas. Valentim.; MOURA, Gilsamara. O processo de criação colaborativa e a questão da autoria na dança: novos paradigmas e outros entendimentos. In: ENICECULT - I Encontro Internacional de Cultura, Linguagens e Tecnologia do Recôncavo, 2017, Santo Amaro. Anais 
do ENICECULT - I Encontro Internacional de Cultura, Linguagens e Tecnologia do Recôncavo. Santo Amaro: ENICEULT, 2017. v. 1. p. 1-14.

SETENTA, Jussara Sobreira. O Fazer-dizer do corpo: dança e performatividade. Salvador, EDUFBA, 2008.

SILVA, Bárbara Conceição Santos da. A tessitura de sentidos na composição improvisada em dança: como o dançarino cria propósitos para a cena. Dissertação (Mestrado). Pós-Graduação em Artes Cênicas, Universidade Federal da Bahia, Salvador, 2012.

SILVA, Suzane Weber. Um modo particular de composição: a improvisação. In: DE ALMEIDA, Marcia Almeida. (Org.). A cena em foco: artes coreográficas em tempos líquidos. Brasília: Editora IFB, 2015, p. 11 22 .

Recebido em agosto de 2020. Aprovado em setembro de 2020. Publicado em outubro de 2020. 